\title{
Editorial
}

\section{Food Polymers Functionality and Applications}

\author{
Xingxun Liu, ${ }^{1}$ Fengwei Xie, ${ }^{2}$ Xiaoxi Li, $^{3}$ Sumei Zhou, ${ }^{1}$ and Liyan Chen ${ }^{4}$ \\ ${ }^{1}$ Institute of Food Science and Technology (IFST), Chinese Academy of Agricultural Sciences, Beijing, China \\ ${ }^{2}$ Australian Institute for Bioengineering and Nanotechnology, The University of Queensland, Brisbane, QLD 4072, Australia \\ ${ }^{3}$ School of Light Industry and Food Science, South China University of Technology, Guangdong, China \\ ${ }^{4}$ Bioprocessing Lab, Prairie Aquatech, Brookings, SD 57006, USA
}

Correspondence should be addressed to Xingxun Liu; ytboy652@163.com

Received 18 October 2015; Accepted 19 October 2015

Copyright ( $\odot 2015$ Xingxun Liu et al. This is an open access article distributed under the Creative Commons Attribution License, which permits unrestricted use, distribution, and reproduction in any medium, provided the original work is properly cited.

Food polymers are polymers from edible plants, animals, and microorganisms that can be used in food systems, including proteins, polysaccharides, and peptides. Generally, food polymers can be classified into three groups based on their sources: (1) plant-based food polymers, such as starch, dietary fiber, and cereal protein; (2) animal-based food polymers, such as meal protein; (3) microorganism-based food polymers, such as fungus polysaccharides. The oils and/or lipid from plant and animals could also be considered as food polymers although their molecular weights are relatively small.

Food polymers represent a dominant area in natural polymers and play an important role in food structure, food functional properties, food processing, and shelf life. The knowledge in this area is commercially important as it will provide a useful practical guideline to food development and industrial production. The new studies of food polymers regarding "molecular design, synthesis/extraction/modification, structure and property, materials preparation, and applications" will give new directions of food science. Therefore, the study of food polymers for food applications could provide a better understanding of food systems, make better use of food macromolecules, and improve food qualities and safety.

In recent years, with the development of fundamental theories and analytical techniques that are related to polymers, specifically food polymers also experience a rapid development with the purpose of improving food systems. This special issue of this journal aims to provide a great opportunity for researchers in the area of food polymer functionality and applications to share their state-of-the-art studies related to food polymers (such as proteins, polysaccharides, and food polymer modifiers). In this special issue, there are original research and review articles that uncover the development of food polymers, including their design, processing, characterization, and microstructures, as well as new technologies related to food polymer processing and characterization. The topics in this special issue specially include the following: (i) new techniques of extracting and modifying food polymers; (ii) recent development in microstructure and nanostructure of food polymers; (iii) the relationship between structures and functionality of food polymers; (iv) novel characterization techniques of food polymers; (v) prospective applications for food polymers.

We hope readers will benefit for their own research from this special issue.

\section{Acknowledgments}

We would like to express our appreciation to all the authors for their informative contributions and the reviewers for their support and constructive critiques in making this special issue possible.

Xingxun Liu Fengwei Xie Xiaoxi $\mathrm{Li}$ Sumei Zhou Liyan Chen 

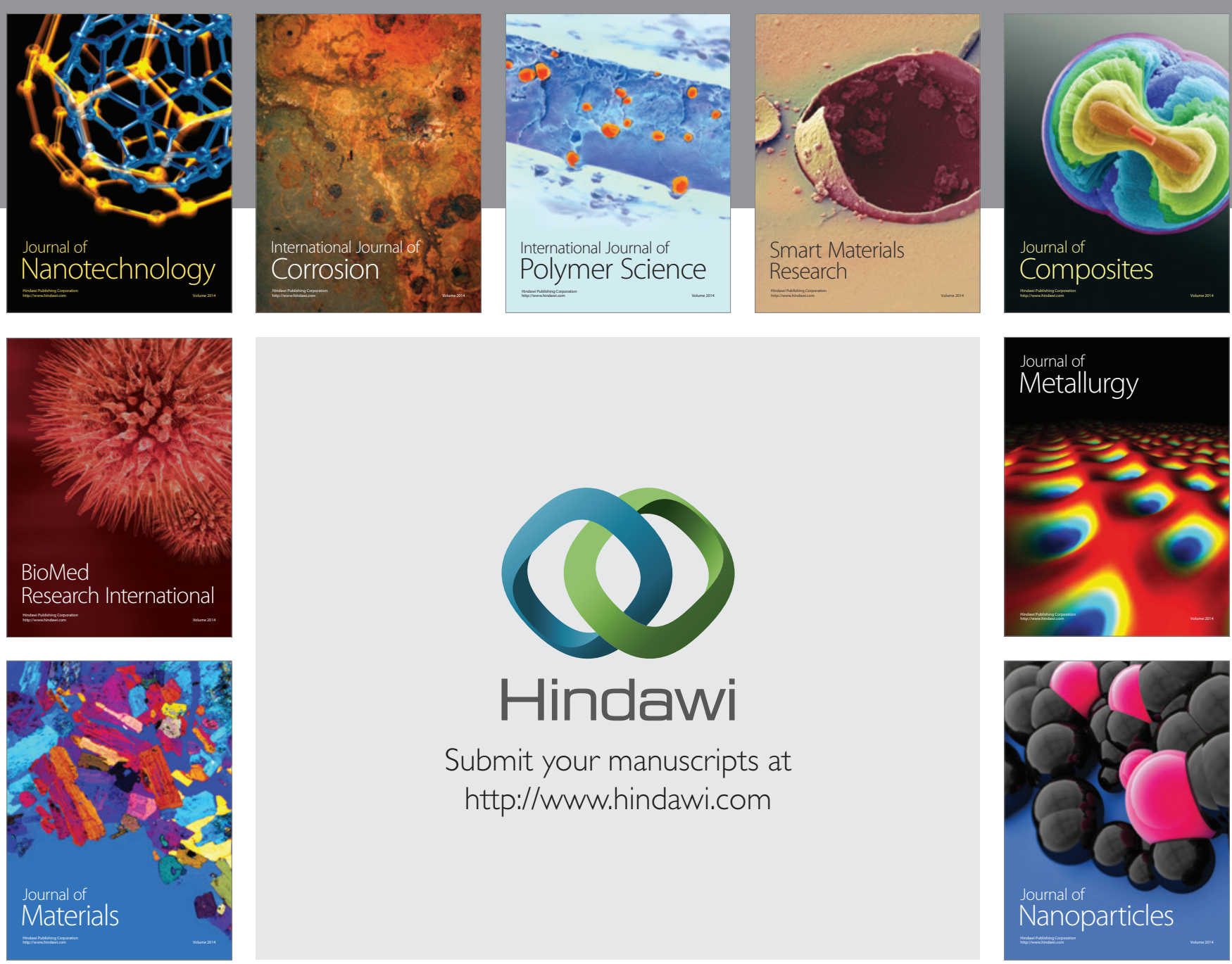

Submit your manuscripts at http://www.hindawi.com
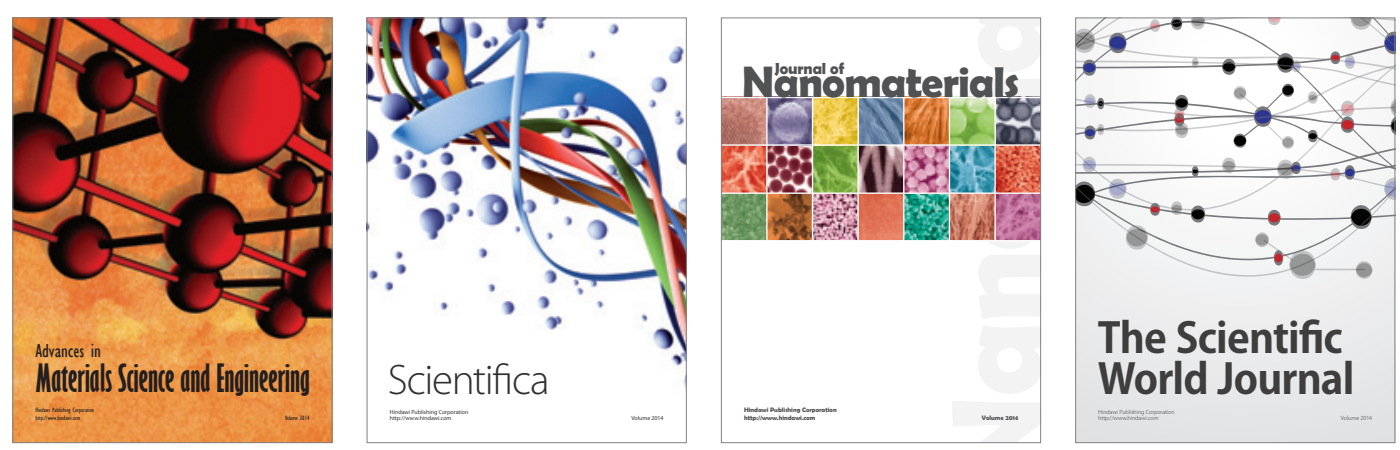

\section{The Scientific World Journal}
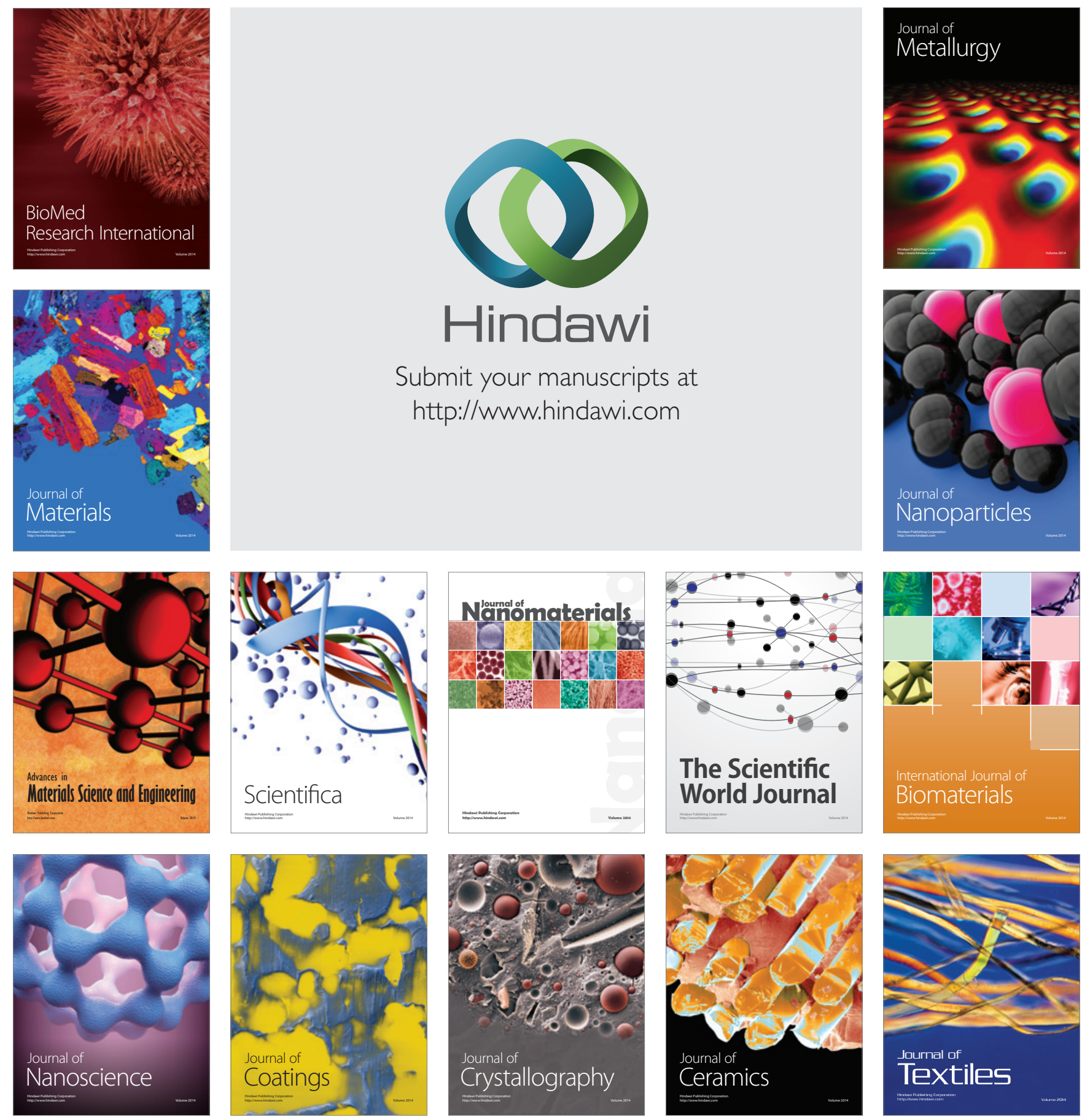